\title{
Improving initial interior egg and egg shell quality through selective breeding
}

H. M. Hyre

Follow this and additional works at: https://researchrepository.wvu.edu/ wv_agricultural_and_forestry_experiment_station_bulletins

\section{Digital Commons Citation}

Hyre, H. M., "Improving initial interior egg and egg shell quality through selective breeding" (1960). West Virginia Agricultural and Forestry Experiment Station Bulletins. 442.

https://researchrepository.wvu.edu/wv_agricultural_and_forestry_experiment_station_bulletins/418 


\section{Digitized by the Internet Archive in 2010 with funding from \\ Lyrasis Members and Sloan Foundation}




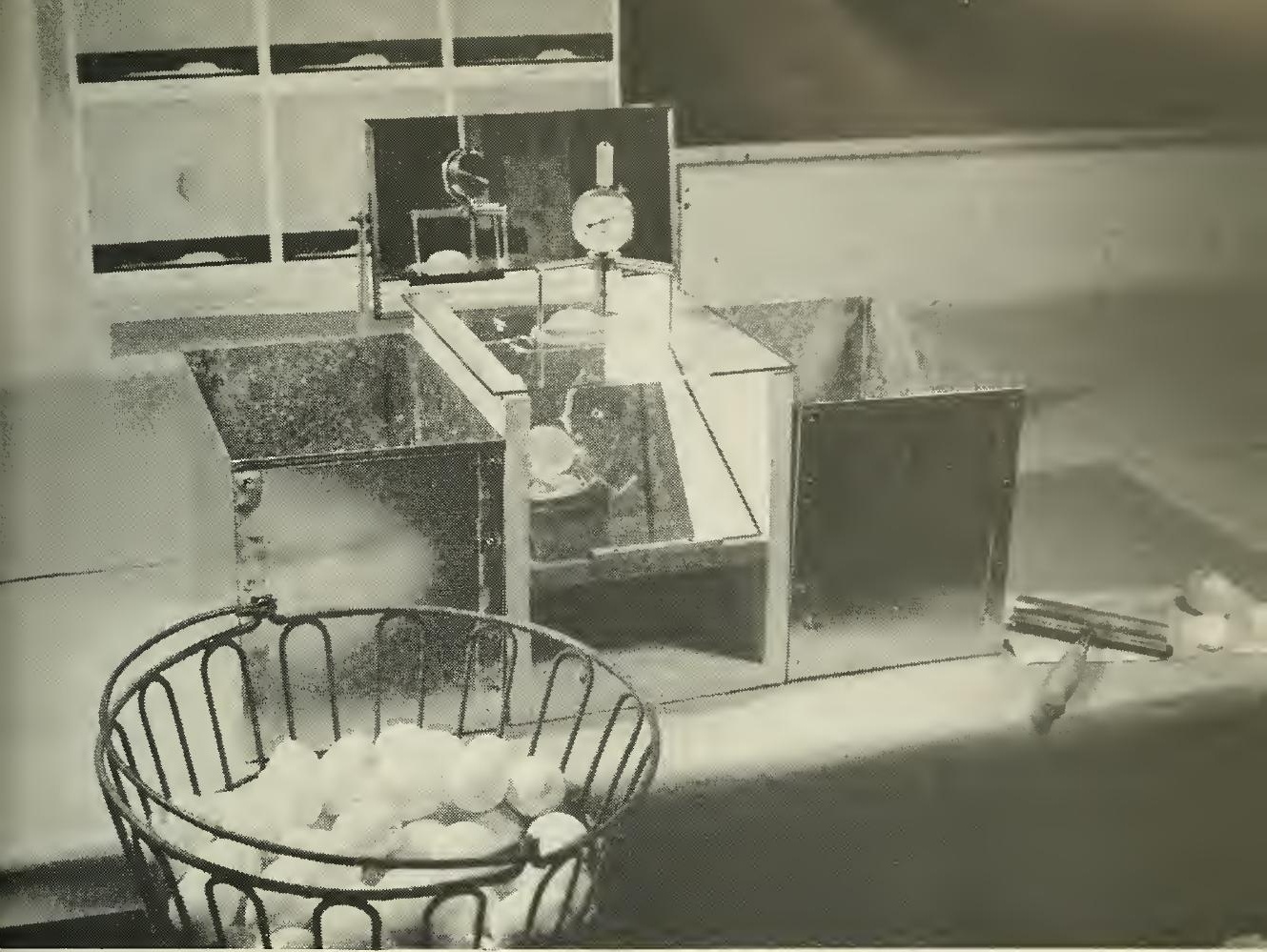

ALBUMEN HEIGHT BEING MEASURED WITH A MICROMETER

\section{Improving Initial Interior Egg and Egg Shell}

\section{Quality Through Selective Breeding}




\title{
THE AUTHOR
}

Author of Improving Initial Interior Egg and Egg Shell Quality Through Selective Breeding is H. M. Hyre, Associate Poultry Scientist in the Agricultural Experiment Station and Associate Professor of Poultry Science in the College of Agriculture, Forestry, and Home Economics.

\author{
West Virginia University \\ Agricultural Experiment Station \\ College of Agriculture, Forestry, and Home Economics \\ A. H. VanLandingham, Director \\ MORGANTOWN
}




\section{Improving Initial Interior Egg and Egg Shell Quality Through Selective Breeding}

\section{Introduction}

H. M. HYRE

THE interior quality of hens' eggs is based primarily on the thickness of the albumen. The United States Department of Agriculture has divided the degrees of egg quality into a series of market grades consisting of $\mathrm{AA}, \mathrm{A}, \mathrm{B}$, and $\mathrm{C}$, and these grades have been divided into U.S.D.A. quality scores ranging from 1 to 12 . Three scores are used for each grade; high, average, and low. The broken-out appearance of these grades and scores may be seen in Figure 1.

Both inheritance and environment influence interior egg quality. Environment can cause the interior quality of an egg to deteriorate but cannot improve it. Therefore if we are to have high-quality eggs they must be so produced. Since egg quality is inherited, this trait may be improved through a selective breeding program for thick albumen. There is a wide variation in the interior quality of new laid eggs from hens within the same flock. Certain hens persistently lay eggs of high quality, whereas others lay eggs of medium quality and still others produce poor-quality eggs. The fact remains, however, that although there is a variation in the interior quality of new laid eggs, most new laid eggs are of good quality.

Another fact regarding egg quality that must not be overlooked is that initial interior quality of eggs decreases with length of lay. An individual hen will produce her best egg quality when she first starts to lay as a pullet. As the laying year progresses the initial interior egg quality will gradually decrease and will be at its lowest near the end of the laying year. This decrease in egg interior quality from the beginning to the end of the laying period is greater in some hens than in others.

Shell strength or shell thickness is another economic trait which poultry breeders must give some attention. Shell thickness is similar to initial interior egg quality in some respects. It is inherited, is at its best when pullets first start to lay, and decreases with length of lay. Shell strength is at its poorest near the end of the laying year. 


\section{INTERIOR QUALITY OF EGGS}

(Recommended standards for scoring the quality of broken-out eggs)

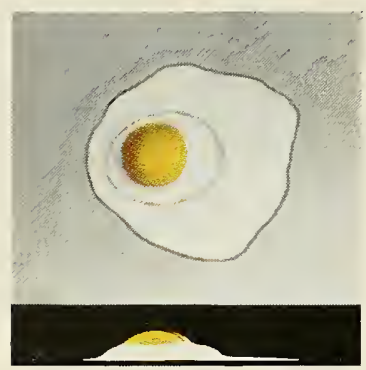

1. HIGH "AA"

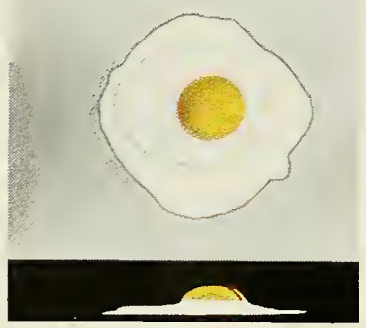

4. $\mathrm{HIGH}^{\text {"A" }}$

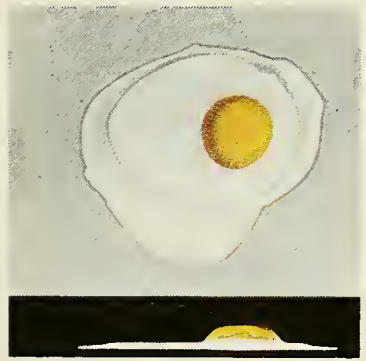

7. HIGH "B"

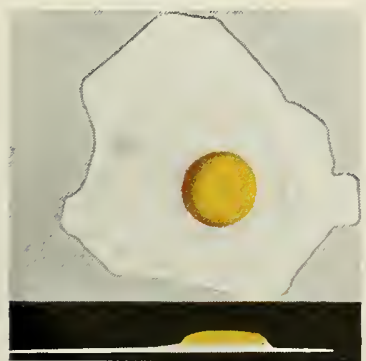

10. HIGH "C"

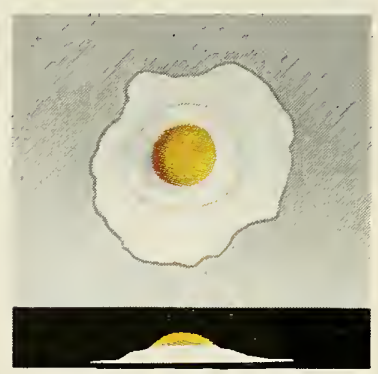

2. AVERAGE "AA"

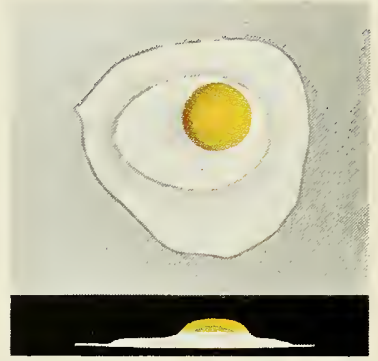

5. AVERAGE "A"

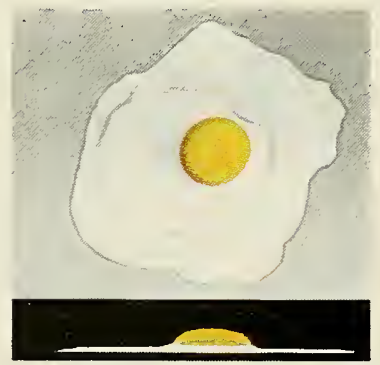

8. AVERAGE "B"

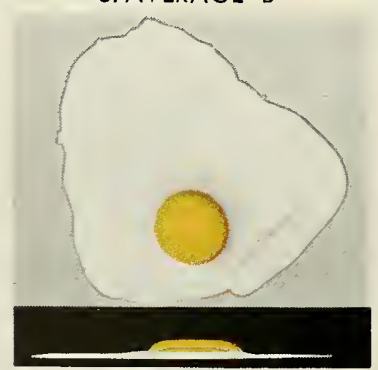

11. AVERAGE " $\mathrm{C}$ "

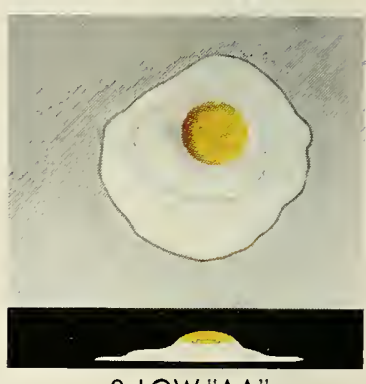

3 LOW "AA"

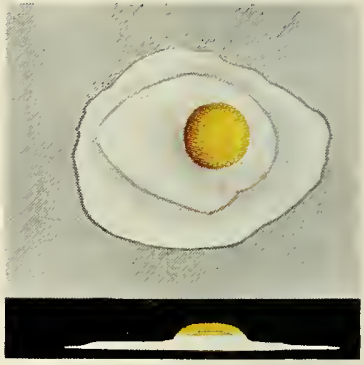

6 LOW "A"
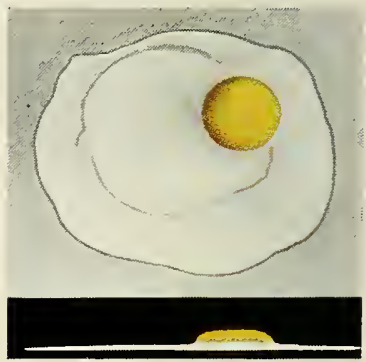

9. LOW "B"

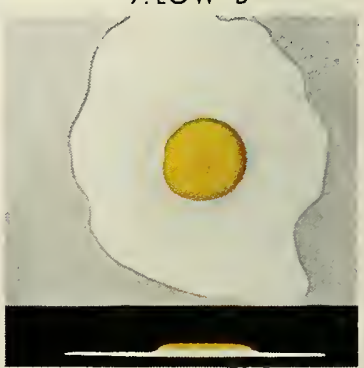

12. LOW "C"

FIGURE 1. Reproduction of U. S. Department of Agriculture color chart showing eggs of interior quality specified in U. S. standards of quality. 
Since both initial interior egg quality and shell quality are at their lowest near the end of the laying year, the most critical test can be made at this time and this is perhaps the best time to select for these traits.

\section{Review of Literature}

Basis for the foregoing statements came from the findings of various poultry research workers and data collected in this study.

Froning and Funk (1958) found that initial interior egg quality decreases with length of lay. Hunter, Van Wagenen, and Hall (1936) showed that there was a seasonal trend in the initial interior quality of hens' eggs from a flock of birds that started to lay in October. The lowering of the quality began about March and continued through the summer. Lorenz and Almquist (1936) observed that egg weight decreased as air temperature was increased during the formation of the egg. Percentages of firm albumen and shell weight, however, were not affected by air temperature during this time.

From the inheritance standpoint, Lorenz, Taylor, and Almquist (1934) stated that there are genetic factors which control, at least in part, the percentage of firm albumen of chicken eggs.

Wilhelm and Heiman (1936) showed that White Leghorn pullets kept under the same environmental conditions had the individual characteristic of producing eggs which had a relatively constant albumen index. Knox and Godfrey (1940) developed two lines of chickens for percentage of thick albumen. After five years of selection the high line had a mean of 68.8 per cent of thick albumen and the low line a mean of 46.9 per cent. These investigators found that eggs with initial high quality retained the thick albumen longer than eggs with low quality when laid. Munro (1936) found that eggs which possess larger than average percentages of firm albumen when laid tend to liquify less rapidly than eggs of lower quality when laid. Holst and Almquist (1931) found that as eggs lose moisture a gradual liquification of the firm albumen occurs. Quinn, Gorclon, and Godfrey (1946) showed that the eggs with strong shells retain their interior quality longer than eggs that have thin shells. Olsson (1934) showed that shell strength could be determined by ascertaining the specific gravity of the whole egg. Novikoff and Guttericlge (1949) found the specific gravit! method of determining shell strength to be less variable than other methods which they compared. This would mean that a much smaller percentage of the eggs would incorrectly fall above or below the set standard. 


\section{Experimental}

The White Leghorn flock at the West Virginia University Agricultural Experiment Station was used for this study. The Cornell University random-bred population of White Leghorns was used as a control. The study was started in the fall of 1954 and terminated in June 1959, and involved the determination of initial interior egg quality and shell strength. The principal purpose of the study was to ascertain the accuracy of determining egg quality by observing the appearance of the broken-out egg. Another phase of the project was to determine whether or not the egg quality of this flock could be improved through selective breeding. The interior quality of the eggs was determined by the U.S.D.A. scoring method. After the weight (in grams) of each egg had been recorded they were broken out on a plate glass and an eye score given by observation. Then, the height of the albumen was determined by the use of a micrometer. The actual U.S.D.A. score was obtained from the interior quality calculator for eggs (Figure 2) by the use of the albumen height and the weight of the egg.

Data on the pullet llock were collected late in November and then again on the same flock in June, which was near the end of the laying year. The birds were trapped and the eggs marked for three consecutive days and all eggs collected were used in the study. The eggs were held overnight and observations and measurements made the following day.

Shell strength was determined by the specific gravity method using a series of salt solutions. Specific gravity of the solution ranged from 1.058 to 1.102 , with intervals of .004 between salt solutions. Specific gravity score ranged from 0 to 11 , with 0 equaling 1.058 specific gravity.

\section{Results}

Table 1 gives the United States Department of Agriculture eye score and measured score of initial interior quality for each of the five years of the study. Data were collected and scores determined for November and June of each year. It can be noted from these data that the scores are lower (the lower the score the higher the quality) during the fall than they are during the summer after the birds had produced for a period of approximately ten months. It may also be noted that the initial interior egg quality was improved by selective breeding. At the beginning of the study in November 1954 the mean measured U.S.D.A. score for the flock was 2.55 and during the same month for the last year of the project, 1958, the measured U.S.D.A. score was 1.82. For 


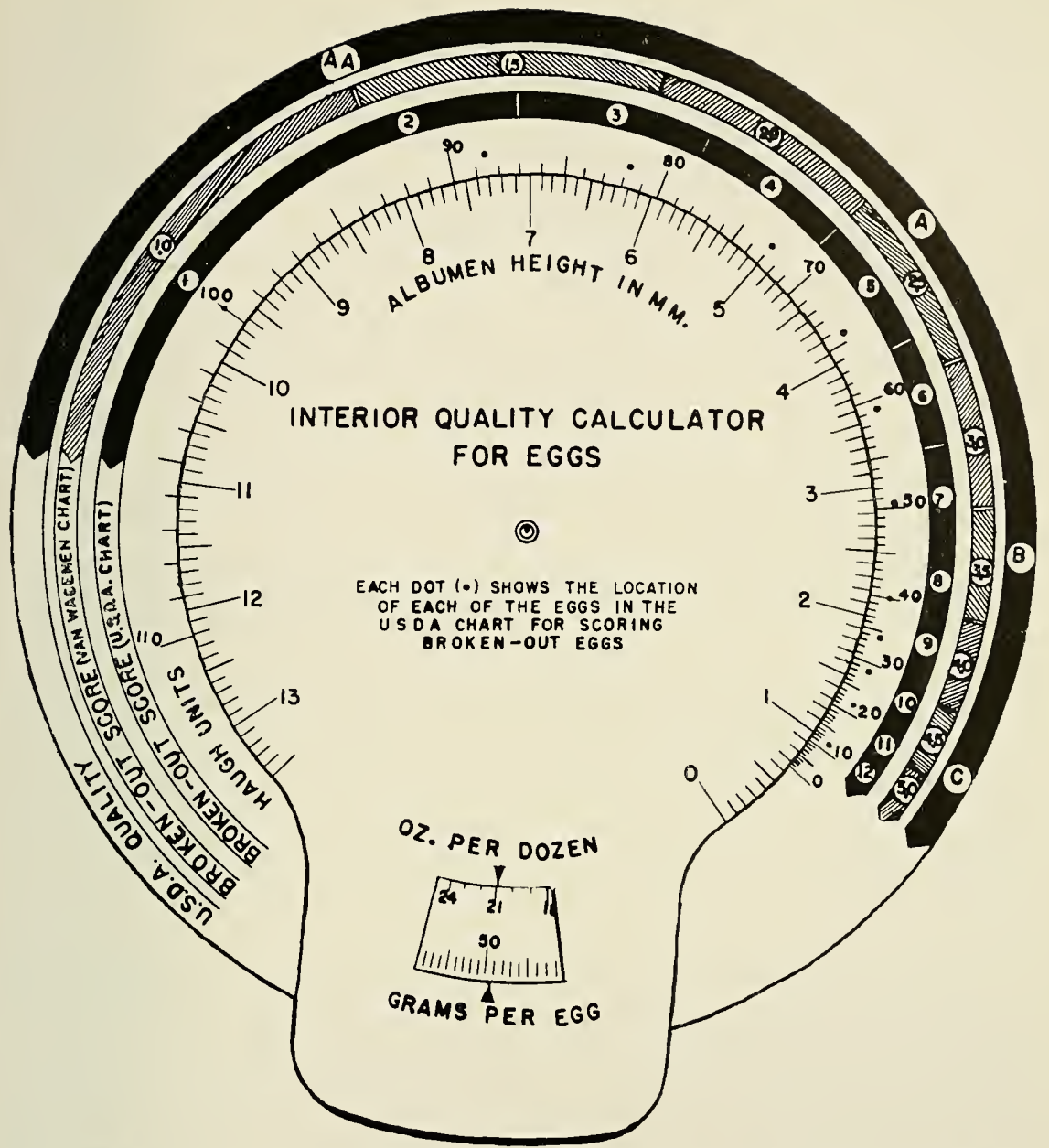

FIGURE 2. The interior quality calculator for eggs. The Haugh units are calculated from albumen height and egg weight. It also shows the relationship of Haugh Units to USDA scores, Van Wagenen scores, and USDA qualities.

the month of June the score at the start of the project was 3.61 and graclually improved to 2.28 for 1958 . For some unknown reason the interior quality for June of the last year dropped to 3.15. It is assumed that the cause was environmental since the interior egg quality of the control flock dropped about the same amount.

The U.S.D.A. eye score for initial interior egg quality was compared with the measured score and correlation coefficients were determined for some of the periods. Table 2 gives these correlations. 
Table 1. Average Interior Egg Quality Score for Nonember and JUNE, 1954-1958

\begin{tabular}{|c|c|c|c|c|c|}
\hline \multirow[b]{2}{*}{ Year } & \multicolumn{2}{|c|}{ November } & \multirow[b]{2}{*}{ Year } & \multicolumn{2}{|c|}{ June } \\
\hline & $\begin{array}{c}\text { Eye } \\
\text { Score }\end{array}$ & $\begin{array}{l}\text { Actual } \\
\text { Score }\end{array}$ & & $\begin{array}{c}\text { Eye } \\
\text { Score }\end{array}$ & $\begin{array}{l}\text { Actual } \\
\text { Score }\end{array}$ \\
\hline & \multicolumn{5}{|c|}{ Experimental Flock } \\
\hline 1954 & 2.48 & 2.55 & 1955 & 3.61 & 3.61 \\
\hline 1955 & 2.31 & 2.13 & 1956 & 3.33 & 3.35 \\
\hline 1956 & 1.90 & 1.93 & 1957 & 2.48 & 2.51 \\
\hline 1957 & * & * & 1958 & 2.17 & 2.28 \\
\hline 1958 & 1.44 & 1.82 & 1959 & 3.24 & 3.15 \\
\hline \multicolumn{6}{|c|}{ Control Flock } \\
\hline 1956 & 2.67 & 2.77 & $195 \bar{\jmath}$ & 3.10 & 3.42 \\
\hline 1957 & * & * & 1958 & 3.30 & 3.32 \\
\hline 1958 & 2.27 & 2.86 & 1959 & 4.08 & 4.56 \\
\hline
\end{tabular}

*Data were not collected for this period.

Table 2. Relationship Between U.S.D.A. Eye Score and U.S.D.A. MeAsured Score For INITIAL INTERIOR QuAlity For White LEGHORN EGGS

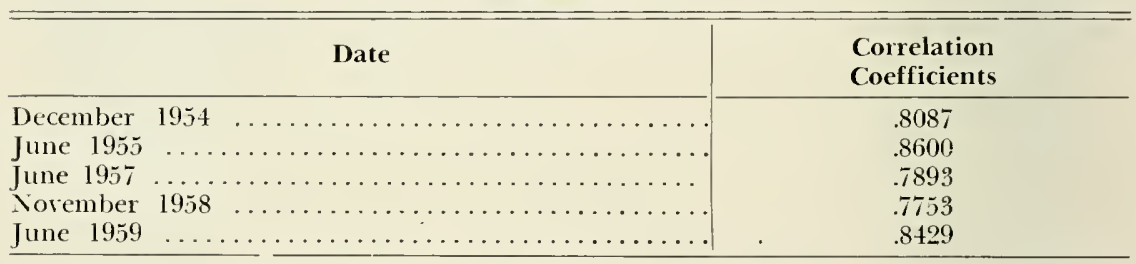

These correlations indicate that it is possible to determine with fair accuracy the interior quality of eggs by observing the broken-out appearance of the contents. Since egg quality is inherited and can be improved by selective breeding, the eye scoring method could be used by poultry breeders to improve interior egg quality of their strains. This method consumes much less time and is less expensive than the measured scoring method. It would be best, however, for anyone wishing to determine the interior quality of eggs from the broken-out appearance to first determine the quality by measurements so as to familiarize himself with the appearance of the various scores and grades.

The mean specific gravity score of the eggs for the various years and periods have been listed in Table 3. The score indicates shell thickness or shell strength, and the higher the score the greater the shell strength. An egg with a score of 5 or better would have satisfactory shell strength. Table 3 shows that shell thickness was greater in the fall, soon after the pullets started to lay, than it was in the early summer after the bircls had laid for a period of about ten months. It may be 
Table 3. Mean Specific Gravity of Eggs from the Flock in the Selective Breeding Project for November And June 1954-1958

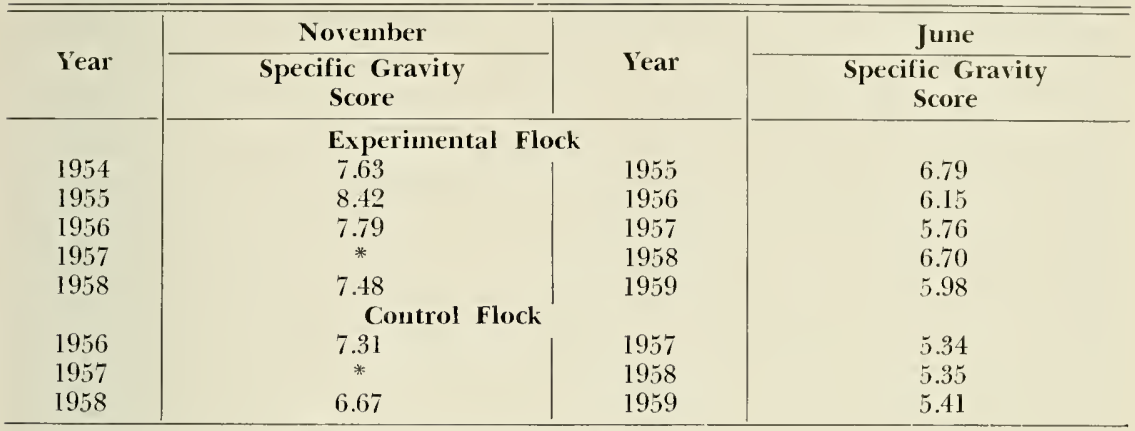

*Data were not collected for this period.

noted that no improvement was made in shell strength during the fiveyear period of selection. This may be clue to a lack of sufficient selection pressure.

Figure 3 shows a method of determining the specific gravity of the solutions. A specific gravity hydrometer is used for this purpose. All solutions to be used must be checked at the beginning of each work period and adjusted if necessary to the correct specific gravity. The specific gravity of a solution will change over a period of time due to evaporation, temperature changes, and usage of the solution.

\section{Summary}

This study was designed to determine the feasibility of improving initial interior egg quality by selecting the breeding hens from observations made on broken-out eggs, and the possibility of improving egg shell quality by selecting breeding hens that lay eggs with a specific gravity above the set standard.

For this work the White Leghorn flock of the West Virginia University Agricultural Experiment Station and the Comell University random-bred population of White Leghorns were used. The initial interior egg quality of the llock was improved through selective breeding

A high correlation existed between the eye score and measured score for egg quality. This would indicate that improvement can be made by selecting on the appearance of the broken-out egg.

Both the initial interior egg quality and the shell strength were higher soon after the pullets started to lay than they were near the end of the laying period. 


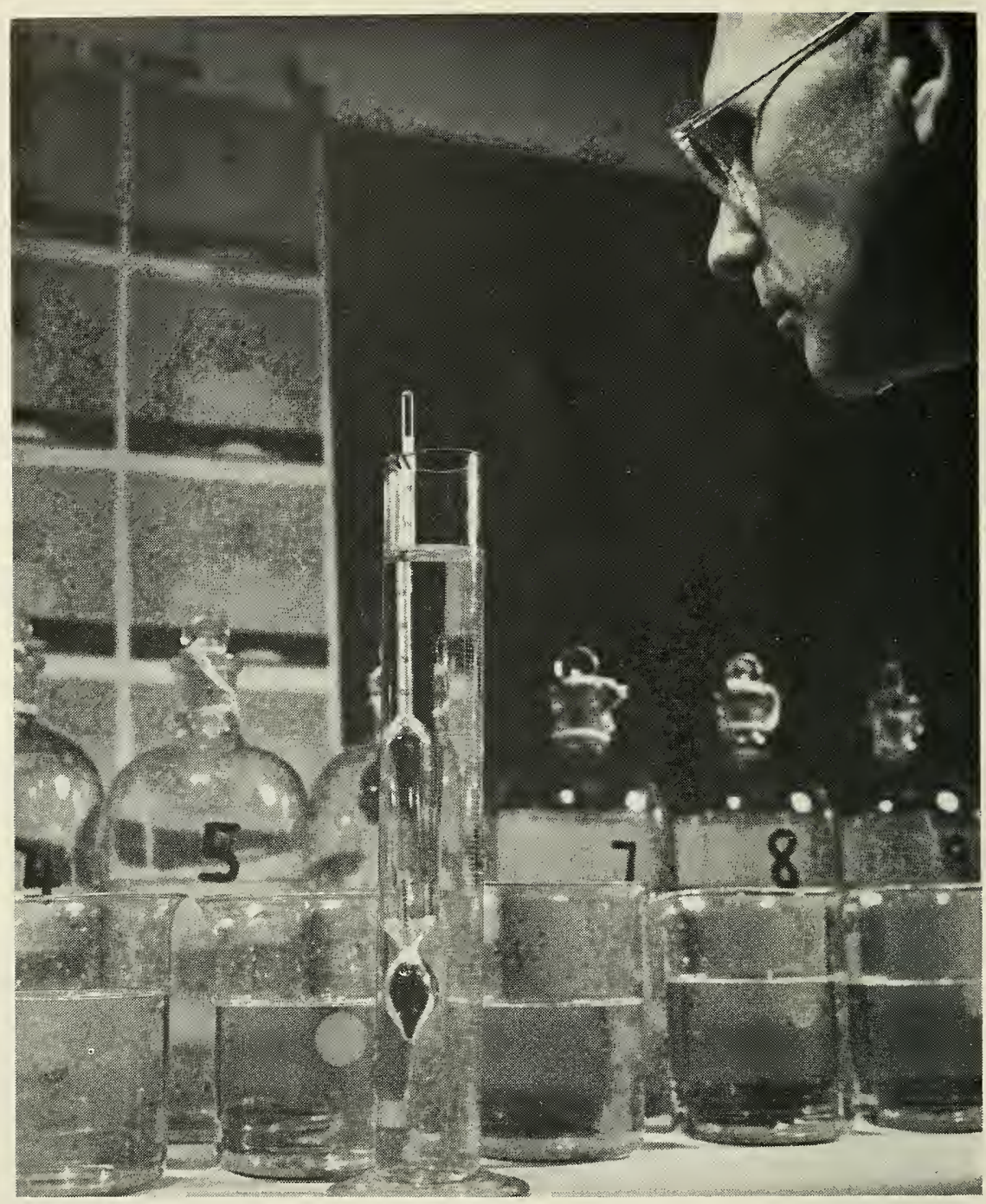

FIGURE 3. A method of determining the specific gravity of a salt solution by the use of a specific gravity hydrometer.

There was no improvement made in shell strength during the study, probably due to a lack of sufficient selection pressure. 


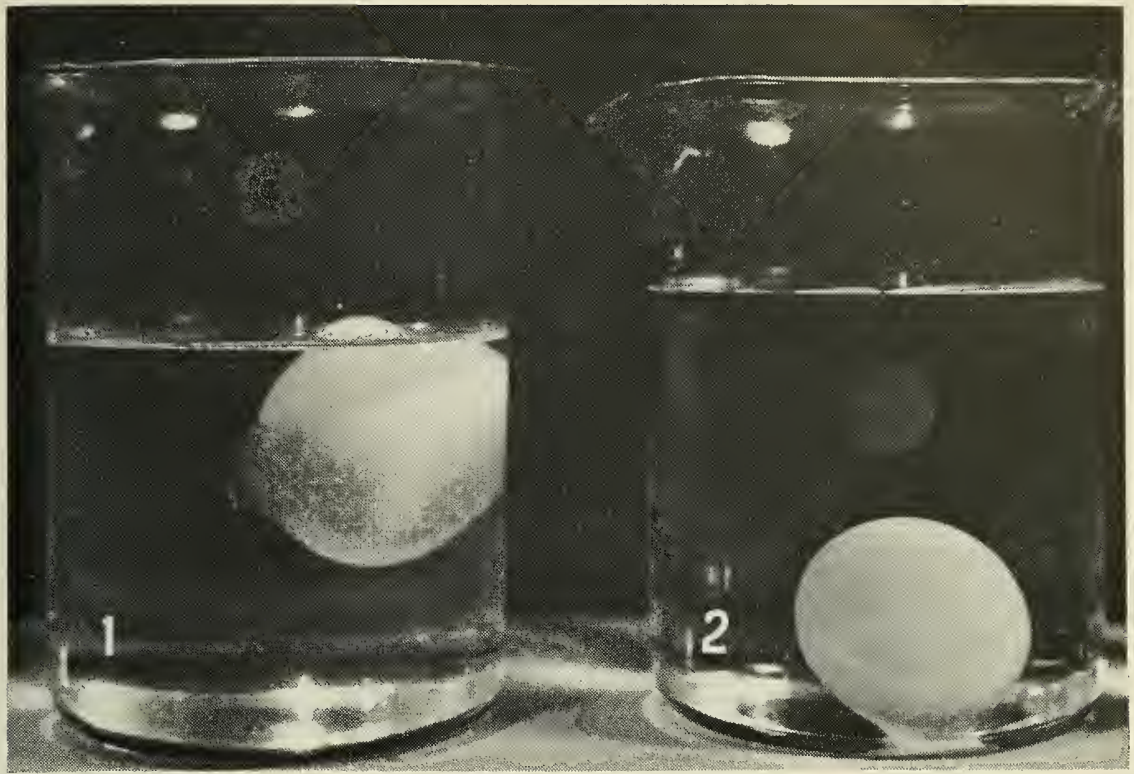

FIGURE 4. Egg 1 has a thinner shell than Egg 2 as shown by the specific gravity test. The solution that contains Egg 1 has a lower specific gravity than the other solution, yet Egg 1 is floating while Egg 2 is on the bottom.

\section{References}

Froning, G. W. and E. M. Funk., 1958. Seasonal variation in quality of eggs laid by caged layers and their sisters on the floor. Poultry Science, 37: 215-223.

Holst, W. F. and H. J. Almquist., 1931. Measurement of deterioration in the storage of hens' eggs. Helganradia, 6: 49-60.

Hunter, J. H., A. Van Wagenen, and G. O. Hall., 1936. Seasonal changes in interior egg quality of Single Comb White Leghorn hens. Poultry Science, 15: 115-118.

Knox, C. W. and A. B. Godfrey., 1940. Fire years of breeding for high and low percentage of thick albumen in the eggs of Rhode lsland Reds. Poultry Science, 19: $291-294$.

Lorenz, F. W., and H. J. Almquist. 1936. Seasonal variation in egg quality. Poultry Science 15: 14-18.

L. W. Taylor, and H. J. Almquist., 1934. Firmmess of albumen as an inherited characteristic. Poultry Science, 13: 14-17.

Munro, S. S., 1936. Correlation between certain fresh and storage measurements of yolk and white. Proc. VI. World's Poultry Congress. Berlin-Lupzig. 224-226.

Norikoff, Morris and H. H. Gutteridge., 1949. A comparison of certain methods of estimating shell strength. Poultry Science, 28: 339-343.

Olsson, N., 1934. Studies on specific gravity of hens' eggs. Otto Harrassowitz Leipzig. $1-64$.

Quinn, J. P., D. C. Gordon, and A. B. Godfrey., 1946. Keeping quality of shell eggs can be improved through breeding. U. S. Egg and Poultry Magazine, 52: 319-380.

Wilhelm, L. A. and V. Heiman., 1936. The constancy of the atbumen index of eggs from individual hens. $U$. S. Egg and Poultry Magazine, 42: (16) 750-75l. 


